\title{
Potassium-induced release of endogenous glutamate and two as yet unidentified substances from the lateral line of Xenopus laevis
}

\author{
Sanford C. Bledsoe Jr., John D. McLaren and Jeffrey R. Meyer \\ Kresge Hearing Research Institute, University of Michigan Medical School, Ann Arbor, MI 48109-0506 (U.S.A.)
}

(Accepted 10 January 1989)

Key words: Neurotransmitter release; Frog lateral line; Hair cell; Glutamate; Aspartate; High performance liquid chromatography

\begin{abstract}
The release of endogenous glutamate and other primary amines from the lateral line of Xenopus laevis was studied using an in vitro superfusion technique and high performance liquid chromatography. Potassium stimulation (50 mM KCl) applied to 60 or 120 lateral-line organs dissected from the skin and pooled in a perfusion chamber induced the release of glutamate and aspartate. The release of aspartate was smaller than that of glutamate and more variable. A variable release of two, as yet, unidentified substances was also detected. In low calcium $(0.1 \mathrm{mM} \mathrm{CaCl})$, high magnesium (10 $\mathrm{mM} \mathrm{MgCl}$ ) solution, $50 \mathrm{mM}$ potassium failed to induce an increase in glutamate, aspartate and the two unknowns, suggesting they are released in a transmitter-like manner. The technique presents a new and simple method for studying transmitters in hair-cell systems. Although other interpretations are possible, the results are consistent with the hypothesis that glutamate is a hair-cell transmitter and suggest a potential role for other substances in the transduction process, perhaps as neuromodulators.
\end{abstract}

\section{INTRODUCTION}

Octavolateralis organs comprise a group of sensory structures that includes the inner ear of mammals and lateral-line system of fishes and aquatic amphibia $^{21,34}$. In the sensory epithelium of these organs, mechanically sensitive hair cells synapse with afferent nerve fibers of the central nervous system. A key step in transduction is the release from hair cells of a chemical transmitter that diffuses across the synaptic cleft to activate postsynaptic receptors and depolarize the afferent nerve fibers. Although the identity of the hair-cell transmitter has not been conclusively established, there is considerable evidence to support the hypothesis that it may be an excitatory amino acid, perhaps glutamate ${ }^{5,8,14}$.

One transmitter criterion of fundamental importance is to demonstrate that a substance is released from the sensory epithelium by stimulation in a calcium-dependent manner ${ }^{44}$. Previously, we reported that in Xenopus laevis water motion induced a release of glutamate which was significantly greater in fluids bathing skins containing the lateral-line organ than from skins without the lateral line ${ }^{9}$. The present study was undertaken to evaluate the dependence of this release on extracellular calcium, utilizing a superfusion technique to enhance amino acid release and high levels of potassium to depolarize a large number of hair cells. A preliminary report has been presented ${ }^{11}$.

\section{MATERIALS AND METHODS}

Experiments were performed on male or female African clawed frogs (Xenopus laevis). The lateralline organ in this amphibian consists of epidermal structures called stitches that are distributed in rows over the head and along the body of the animal (Fig.

Correspondence: Sanford C. Bledsoe Jr., Kresge Hearing Research Institute, University of Michigan Medical School, 1301 E. Ann Street, Ann Arbor, MI 48109-0506, U.S.A. 


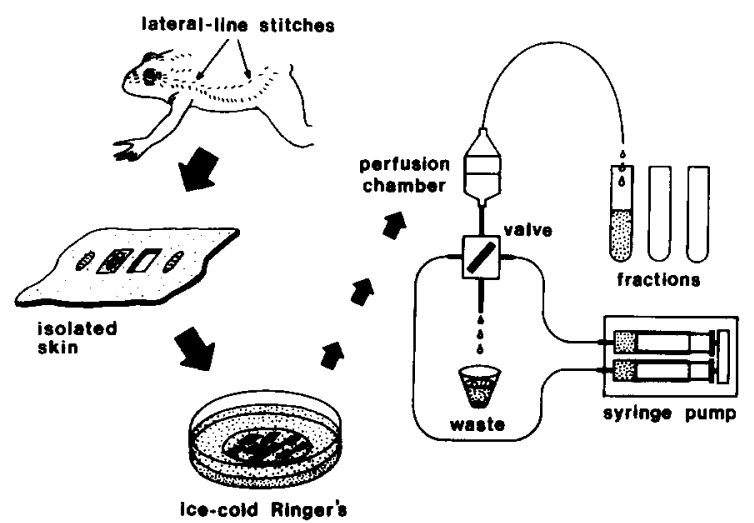

Fig. 1. Schematic of the experimental strategy and perfusion set-up. See text for details.

1). Each stitch contains 3-12 neuromasts in which are located the hair cells and their associated supporting cells ${ }^{30}$.

Frogs were anesthetized by cooling on ice, decapitated and portions of skin containing the dorsal and medial lateral rows of stitches excised. The isolated skins were placed cupular (external) surface up on an ice-chilled petri dish and bathed with frog Ringer solution. Under a dissecting microscope and fiber optic illumination, pieces of tissue (stitch or nonstitch) were cut from the skin with a small scalpel blade (Fig. 1). Histological examination revealed that cuts could be made close to stitches without damage to hair cells. Stitch tissue was harvested from the dorsal and medial lateral rows of stitches and non-stitch pieces of skin of comparable size were obtained from areas between or adjacent to the stitches. The tissue was placed on a glass-fiber filter disc and suspended in ice-cold Ringer solution until utilized.

After dissection, the tissue (stitch or non-stitch) was transferred into a perfusion chamber (vol. 1.0 $\mathrm{ml}$ ) which was attached to a valve that permitted switching between Ringer solutions of different composition (Fig. 1). Perfusates were delivered at room temperature at a flow rate of $520 \mu \mathrm{l} / \mathrm{min}$ via a syringe pump. After a 30 -min wash to establish baseline efflux, 6 consecutive 5 -min fractions for primary amine analysis were collected. The tissue was exposed to perfusate containing $50 \mathrm{mM}$ potassium for 10 min during the collection of the third and fourth fractions. Each fraction $(2.6 \mathrm{ml}$ vol.) was frozen in a dry ice/methanol bath immediately after collection, lyophilized and stored at $-20{ }^{\circ} \mathrm{C}$ until assayed. At the end of an experiment, the tissue was recovered, homogenized and total protein determined by the Coomassie technique (Bio-Rad).

The composition of the standard Ringer solution was (mM): $\mathrm{NaCl} 104.5, \mathrm{KCl} 2, \mathrm{CaCl}_{2} 1.8, \mathrm{Na}_{2} \mathrm{HPO}_{4}$ 2.25, $\mathrm{NaH}_{2} \mathrm{PO}_{4} 0.75(\mathrm{pH} 7.0)$. In $50 \mathrm{mM} \mathrm{KCl}$ solutions an equimolar quantity of $\mathrm{NaCl}$ was removed to avoid osmotic effects. To measure the calcium dependence of release, low-calcium, highmagnesium medium containing $0.1 \mathrm{mM} \mathrm{CaCl}_{2}$ and $10 \mathrm{mM} \mathrm{MgCl}_{2}$ replaced the standard Ringer solution from the initial 30 -min perfusion before potassium stimulation until the end of the experiment.

The concentrations of amino acids and other primary amines were determined by o-phthalaldehyde (OPA) $/ \beta$-mercaptoethanol derivatization ${ }^{22}$ followed by gradient elution high-performance liquid chromatography (HPLC) and fluorometric detection. The chromatography system consisted of two Beckman Model 110A pumps, a Model 420 microprocessor controller and a Model 210 sample injector. The fluorescence detector was a Gilson Spectra/ Glo Model FL-1B fluorometer equipped with a $15 \mu \mathrm{l}$ flow cell and excitation filter of $360 \mathrm{~nm}$ and emission filter peaked at $455 \mathrm{~nm}$. For assay, lyophilized samples were reconstituted in $300 \mu \mathrm{l}$ of methanol/ $\mathrm{H}_{2} \mathrm{O}(8: 2$, by vol.), vortexed vigorously and centrifuged to pellet all particulate material. A $40 \mu \mathrm{l}$ aliquot of the supernatant was derivatized in the following reaction mixture, $\mathrm{H}_{2} \mathrm{O} / 0.4 \mathrm{M}$ sodium borate, $\mathrm{pH}$ 9.5/supernatant/OPA reagent (10:4:4:2, by vol.). The OPA reagent consisted of $10 \mathrm{mg}$ OPA in methanol $/ \mathrm{H}_{2} \mathrm{O} / 0.4 \mathrm{M}$ sodium borate, $\mathrm{pH} 9.5$ (1:8:1, by vol.) to which had been added $10 \mu \mathrm{l}$ of $\beta$-mercaptoethanol as the reducing agent. The derivatization was initiated by the addition of the OPA reagent $(20 \mu \mathrm{l})$ to the reaction mixture and the mixture vortexed for $30 \mathrm{~s}$. Five min after adding the OPA reagent, a $20 \mu \mathrm{l}$ aliquot of the $200 \mu \mathrm{l}$ reaction mixture was injected onto the HPLC column by the sample loop overfill technique. The analytical column consisted of a Beckman $5 \mu \mathrm{m}$ sphere $\mathrm{C}_{18}$ (Ultrasphere, $250 \times 4.6 \mathrm{~mm}$ ) column working at room temperature. It was fitted with a precolumn packed with Perisorb RP-18, 30-40 $\mu \mathrm{m}$ pellicular material.

Separation was achieved at a flow rate of $1 \mathrm{ml} / \mathrm{min}$ 
by a multilinear segmented gradient formed over 60 min using two degassed solvent mixtures. Solvent A (pH 6.8) contained 1\% tetrahydrofuran, 19\% methanol, and $80 \% 0.05 \mathrm{M}$ sodium acetate. Solvent $\mathrm{B}$ (pH 6.8) contained $80 \%$ methanol and $20 \% 0.05 \mathrm{M}$ sodium acetate. Eluted primary amine profiles were recorded simultaneously on a strip chart (Linear Instruments, Model $285-\mathrm{mm}$ ) and an integrating recorder (Hewlett-Packard, Model 3390A). The amino acids in release samples were identified by retention time and quantified by peak height analysis with regard to an external standard. The standard contained 5 pmol of each of the following amino acids: aspartate (Asp), glutamate (Glu), asparagine (Asn), serine (Ser), glutamine (Gln), glycine (Gly), threonine (Thr), arginine (Arg), taurine (Tau), hypotaurine (HTau), alanine (Ala), $\gamma$-aminobutyrate (GABA), tyrosine (Tyr), $\alpha$-aminobutyrate (AABA), methionine (Met), valine (Val), phenylalanine (Phe), isoleucine (ILeu), and leucine (Leu). All were clearly resolved from each other except for GABA and tyrosine which coeluted with the present separation technique. The amount of each amino acid in the reconstituted samples was calculated from the amount detected in the $20 \mu \mathrm{l}$ injection volume. Results were expressed as pmoles/mg protein $/ 5 \mathrm{~min}$ sample. Analysis of variance and Newman-Keuls multiple range tests were used to determine significance $(P<0.05)$ between stimulated and nonstimulated conditions.

\section{RESULTS}

In an initial set of 4 experiments, 60 lateral-line stitches were dissected and superfused with Ringer solution containing normal levels of calcium (1.8 $\mathrm{mM}$ ) for $30 \mathrm{~min}$ prior to depolarization with $50 \mathrm{mM}$ potassium. In all 4 , the potassium stimulus increased the release of glutamate. Since the void volume of the perfusion system was approximately $4 \mathrm{~min}$, the maximum increase was observed in the second 5-min sample (fraction 4 ) after switching to $50 \mathrm{mM}$ potassium (Fig. 2). A small increase in aspartate was also detected in fraction 4 in 3 of the 4 experiments. Fig. 3 depicts chromatograms from one of these experiments. The top chromatogram (designated $2.0 \mathrm{mM}$ $\mathrm{K}^{+}$) was obtained on assay of fraction 2 and the bottom one (designated $50 \mathrm{mM} \mathrm{K}^{+}$) on assay of the potassium-stimulated fraction 4 . Compared to the levels in fraction 2, the amounts of aspartate and glutamate in fraction 4 were increased 21 and $108 \%$ respectively. Most of the other chromatographic peaks were unchanged or slightly decreased by potassium depolarization. Table I lists mean concentrations of 15 amino acids identified in fractions 2 and 4 of the 60 -stitch experiments. The mean values for both glutamate and aspartate are higher in fraction 4 (Table I; column 2) than in fraction 2 (Table I; column 1). However, owing to the variance associated with the small changes in aspartate, only the increase in glutamate was statistically significant. It should be noted that no other amino acids were released by potassium including glutamine, asparagine, glycine, taurine or GABA+tyrosine. In an additional 4 experiments in which 60 stitches were superfused with $0.1 \mathrm{mM}$ calcium, $10 \mathrm{mM}$ magnesium for $30 \mathrm{~min}$ to block transmitter release, potassium stimulation failed to increase the levels of glutamate and aspartate (Table I; columns 3 and 4).

Inspection of Fig. 3 reveals a third substance

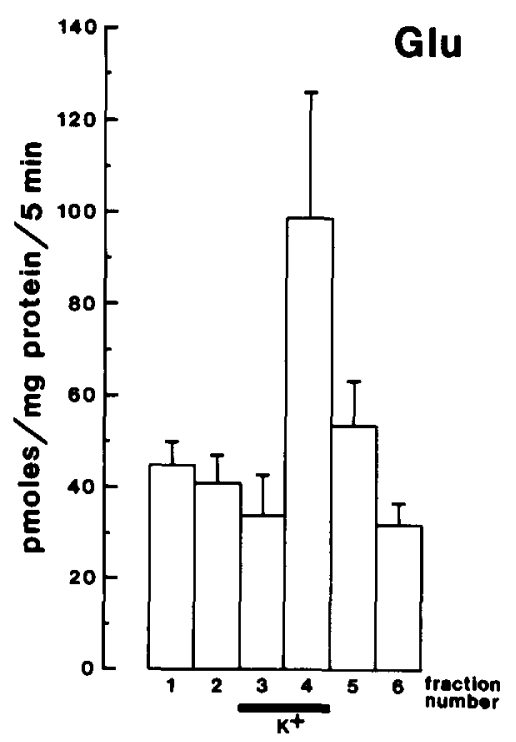

Fig. 2. Time course of glutamate release from 60 lateral-line stitches induced by $50 \mathrm{mM}$ potassium in the presence of calcium $(1.8 \mathrm{mM})$. Six consecutive 5 -min fractions were analyzed and expressed in $\mathrm{pmol} / \mathrm{mg}$ protein $/ 5 \mathrm{~min}$. Bar denotes the stimulation period for the third and fourth fractions during which standard Ringer solution (2.0 mM potassium) was switched to medium containing $50 \mathrm{mM}$ potassium. Column heights are the mean concentrations of 4 independent experiments for the indicated fractions. Vertical lines denote standard deviations of the means. 


\section{TABLE I}

Effect of $50 \mathrm{mM} \mathrm{K}^{+}$on the release of endogenous amino acids from 60 lateral-line stitches and the influence of low $\mathrm{Ca}^{++}$, high $\mathrm{Mg}^{++}$ medium

Four experiments were performed for each of the two $\mathrm{Ca}^{++}$conditions. Values are the mean concentration ( \pm S.D.) for the indicated amino acids and are expressed as pmoles $/ \mathrm{mg}$ protein $/ 5 \mathrm{~min}$.

\begin{tabular}{|c|c|c|c|c|}
\hline \multirow[t]{2}{*}{ Amino acid } & \multicolumn{2}{|c|}{ Normal $\mathrm{Ca}^{++}\left(1.8 \mathrm{mMCa}^{++}\right)$} & \multicolumn{2}{|c|}{ Low $\mathrm{Ca}^{++}, \mathrm{High} \mathrm{Mg}^{++}\left(0.1 \mathrm{mMCa}^{++}, 10 \mathrm{mMMg}^{++}\right)$} \\
\hline & $\begin{array}{l}2.0 \mathrm{mMK} \mathrm{K}^{+} \\
\text {(fraction } 2 \text { ) }\end{array}$ & $\begin{array}{l}50 m M K^{+} \\
\text {(fraction } 4)\end{array}$ & $\begin{array}{l}2.0 \mathrm{mM} \mathrm{K} \mathrm{K}^{+} \\
\text {(fraction } 2 \text { ) }\end{array}$ & $\begin{array}{l}50 m M K^{+} \\
\text {(fraction } 4 \text { ) }\end{array}$ \\
\hline Asp & $30.7 \pm 11.3$ & $44.9 \pm 35.1$ & $28.8 \pm 4.9$ & $25.0 \pm 2.7$ \\
\hline Glu & $41.1 \pm 7.0$ & $98.4 \pm 27.4^{*}$ & $59.4 \pm 8.4$ & $46.9 \pm 8.0$ \\
\hline Asn & $19.3 \pm 1.6$ & $18.5 \pm 2.9$ & $30.8 \pm 7.5$ & $21.7 \pm 3.7$ \\
\hline Ser & $63.3 \pm 19.3$ & $63.0 \pm 11.7$ & $78.7 \pm 6.5$ & $61.2 \pm 5.5$ \\
\hline Gln & $24.8 \pm 6.4$ & $27.3 \pm 11.9$ & $57.4 \pm 14.8$ & $37.9 \pm 8.0$ \\
\hline Gly & $40.1 \pm 19.9$ & $48.2 \pm 1.7$ & $76.1 \pm 15.8$ & $54.1 \pm 5.8$ \\
\hline Thr & $35.0 \pm 5.0$ & $37.6 \pm 5.8$ & $57.2 \pm 17.0$ & $38.8 \pm 10.3$ \\
\hline Arg & $33.2 \pm 12.6$ & $38.8 \pm 9.3$ & $54.4 \pm 7.1$ & $41.3 \pm 5.8$ \\
\hline Ala & $91.2 \pm 36.5$ & $94.8 \pm 15.4$ & $139.0 \pm 35.4$ & $104.3 \pm 9.9$ \\
\hline Tyr + GABA & $32.9 \pm 12.2$ & $48.9 \pm 16.1$ & $95.0 \pm 37.0$ & $76.9 \pm 32.0$ \\
\hline Met & $20.5 \pm 8.1$ & $20.8 \pm 8.3$ & $28.3 \pm 7.8$ & $17.7 \pm 4.0$ \\
\hline Val & $46.9 \pm 10.9$ & $47.3 \pm 7.1$ & $79.3 \pm 14.0$ & $61.5 \pm 5.7$ \\
\hline Phe & $38.6 \pm 9.2$ & $42.7 \pm 7.2$ & $85.8 \pm 17.2$ & $66.1 \pm 8.8$ \\
\hline ILeu & $36.8 \pm 5.6$ & $35.0 \pm 3.5$ & $67.6 \pm 17.6$ & $51.4 \pm 10.7$ \\
\hline Leu & $48.6 \pm 10.4$ & $47.7 \pm 8.9$ & $83.0 \pm 19.1$ & $63.1 \pm 13.4$ \\
\hline
\end{tabular}

* Values obtained with $50 \mathrm{mM} \mathrm{K}^{+}$(fraction 4) significantly different $(P<0.05)$ than $2.0 \mathrm{mM} \mathrm{K}^{+}$(fraction 2 ).

(arrow) that was also increased by $50 \mathrm{mM}$ potassium stimulation. This substance, which we have designated unknown No. 1, eluted from the HPLC
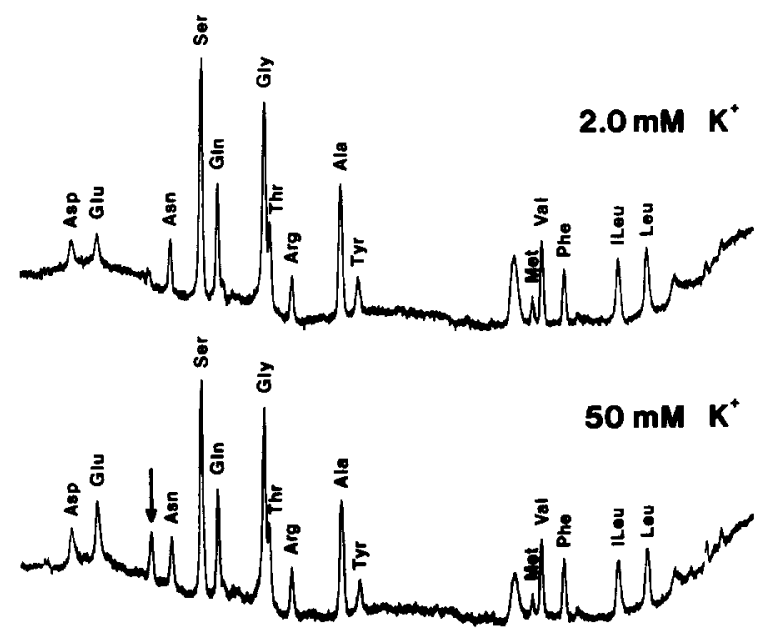

Fig. 3. Chromatograms from one experiment depicting effect of $50 \mathrm{mM}$ potassium on release of primary amines from 60 lateral-line stitches perfused with normal levels of calcium $(1.8$ $\mathrm{mM}$ ). Top chromatogram is unstimulated and was obtained on assay of fraction 2; bottom chromatogram is stimulated and was obtained on assay of fraction 4 . Note small increase in aspartate (Asp), substantial increase in glutamate (Glu) and the appearance of an unidentified substance (arrow) with potassium stimulation.

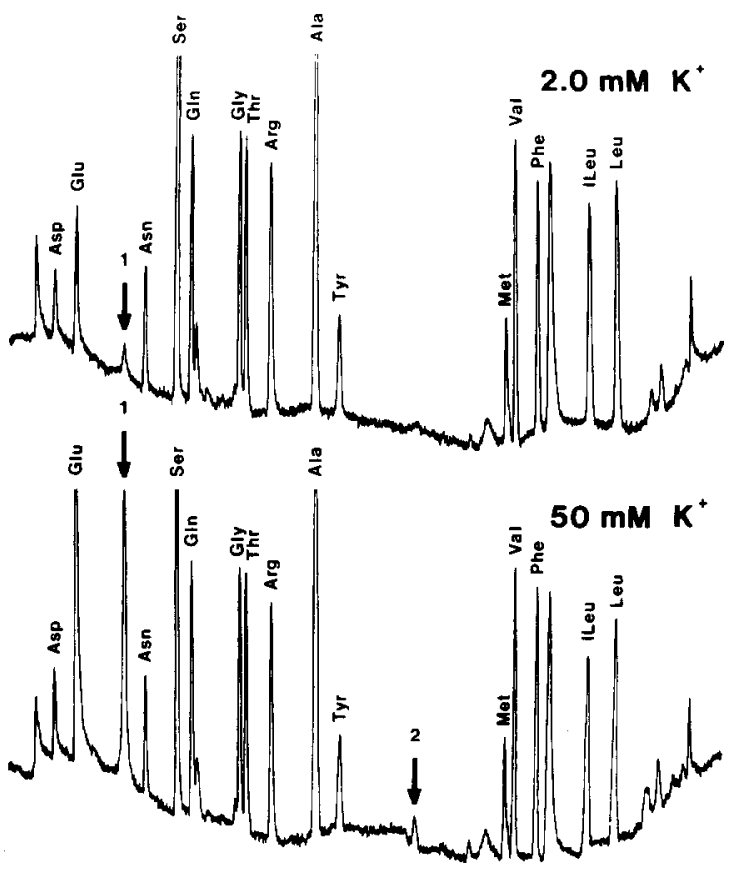

Fig. 4. Chromatograms from one experiment depicting effect of $50 \mathrm{mM}$ potassium on release of primary amines from 120 lateral-line stitches perfused with normal levels of calcium (1.8 $\mathrm{mM}$ ). Chromatograms were obtained on assay of unstimulated fraction 2 (top) and stimulated fraction 4 (bottom). Note increases in aspartate (Asp), glutamate (Glu) and unknown No. 1 (arrow 1) with $50 \mathrm{mM}$ potassium. Also, note the appearance of a second unidentified substance (arrow 2). 
TABLE II

Effect of $50 \mathrm{mM} \mathrm{K}^{+}$on the release of endogenous amino acids from 120 lateral-line stitches and the influence of low Ca ${ }^{++}$, high $\mathrm{Mg}^{++}$ medium

Six experiments were performed for each of the two $\mathrm{Ca}^{++}$conditions. Values are the mean concentration ( \pm S.D.) for the indicated amino acids and are expressed as pmoles $/ \mathrm{mg}$ protein $/ 5 \mathrm{~min}$.

\begin{tabular}{|c|c|c|c|c|}
\hline \multirow[t]{2}{*}{ Amino acid } & \multicolumn{2}{|c|}{ Normal $\mathrm{Ca}^{++}\left(1.8 \mathrm{mMCa}^{++}\right)$} & \multicolumn{2}{|c|}{ 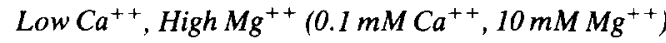 } \\
\hline & $\begin{array}{l}2.0 m M K^{+} \\
\text {(fraction } 2 \text { ) }\end{array}$ & $\begin{array}{l}50 \mathrm{mMK}^{+} \\
\text {(fraction 4) }\end{array}$ & $\begin{array}{l}2.0 \mathrm{mM} \mathrm{K} \mathrm{K}^{+} \\
\text {(fraction 2) }\end{array}$ & $\begin{array}{l}50 \mathrm{mMK}^{+} \\
\text {(fraction 4) }\end{array}$ \\
\hline Asp & $27.4 \pm 6.0$ & $43.0 \pm 22.3$ & $39.7 \pm 6.1$ & $39.8 \pm 8.1$ \\
\hline Glu & $56.4 \pm 10.9$ & $178.0 \pm 80.0^{*}$ & $86.5 \pm 8.7$ & $68.8 \pm 5.0$ \\
\hline Asn & $47.1 \pm 16.9$ & $49.2 \pm 5.2$ & $53.1 \pm 11.5$ & $51.3 \pm 9.9$ \\
\hline Ser & $103.8 \pm 7.9$ & $100.0 \pm 6.4$ & $126.0 \pm 9.4$ & $110.6 \pm 11.8$ \\
\hline Gln & $77.7 \pm 10.8$ & $78.0 \pm 3.5$ & $98.9 \pm 8.2$ & $84.3 \pm 8.5$ \\
\hline Gly & $72.6 \pm 9.8$ & $68.9 \pm 6.3$ & $119.4 \pm 18.9$ & $103.4 \pm 10.8$ \\
\hline Thr & $82.9 \pm 5.1$ & $79.5 \pm 6.1$ & $124.5 \pm 17.0$ & $98.4 \pm 3.8$ \\
\hline Arg & $77.3 \pm 6.6$ & $79.2 \pm 6.0$ & $134.8 \pm 15.9$ & $107.5 \pm 6.5$ \\
\hline Ala & $172.2 \pm 29.6$ & $174.1 \pm 21.2$ & $213.8 \pm 12.4$ & $163.7 \pm 21.9$ \\
\hline Tyr + GABA & $84.9 \pm 16.1$ & $83.5 \pm 11.3$ & $113.7 \pm 10.5$ & $80.8 \pm 12.2$ \\
\hline Met & $50.7 \pm 4.7$ & $47.3 \pm 5.4$ & $57.0 \pm 14.7$ & $49.1 \pm 11.8$ \\
\hline Val & $97.6 \pm 5.8$ & $91.3 \pm 5.0$ & $151.6 \pm 25.6$ & $130.0 \pm 10.5$ \\
\hline Phe & $94.5 \pm 2.7$ & $103.5 \pm 11.1$ & $159.3 \pm 18.5$ & $131.7 \pm 9.4$ \\
\hline ILeu & $86.1 \pm 13.1$ & $75.8 \pm 3.2$ & $149.5 \pm 25.5$ & $124.7 \pm 21.5$ \\
\hline Leu & $101.4 \pm 7.7$ & $93.4 \pm 7.6$ & $196.6 \pm 18.1$ & $156.6 \pm 26.0$ \\
\hline
\end{tabular}

* Values obtained with $50 \mathrm{mM} \mathrm{K}^{+}$(fraction 4) significantly different $\left(P<0.05\right.$ ) from $2.0 \mathrm{mM} \mathrm{K}^{+}$(fraction 2 ).

column between glutamate and asparagine and remains as yet unidentified. It was barely, if at all, detectable in unstimulated samples, but consistently appeared in fraction 4 in the 60-stitch experiments with normal levels of calcium. In the 4 experiments with low-calcium medium, unknown No. 1 was not detected in any of the fractions.

To increase the likelihood of detecting release, 6 experiments were performed in which 120 stitches were dissected, superfused with standard Ringer solution and depolarized with $50 \mathrm{mM}$ potassium for $10 \mathrm{~min}$. Fig. 4 depicts chromatograms from one of these experiments. The results are comparable to those shown in Fig. 3 and the levels of aspartate and glutamate are increased 91 and $150 \%$ respectively. Fig. 5 and Table II (columns 1 and 2) summarize the findings for 15 amino acids identified in fractions 2 and 4 from these experiments. Again, owing to the variance associated with the changes in aspartate, only the increase in glutamate was statistically significant. In 6 experiments in which 120 stitches were superfused with the low calcium medium, 50 $\mathrm{mM}$ potassium again failed to increase the levels of glutamate and aspartate (Table II; columns 3 and 4).

Unknown No. 1 was also released by potassium in the presence of calcium in 5 of the 6 experiments with 120 stitches (Fig. 4). The magnitude of this increase was as great as 10-fold in two of the experiments. In addition, inspection of Fig. 4 reveals another unidentified substance (arrow 2) which appeared in fraction 4 in 5 of the 6 experiments. In

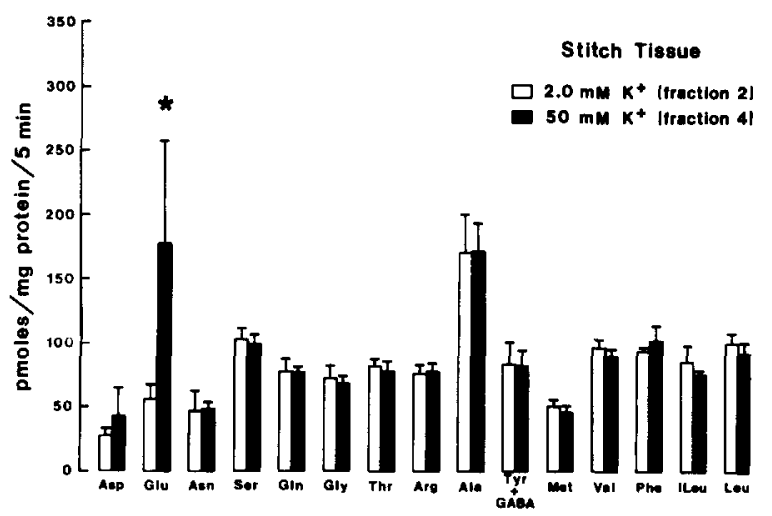

Fig. 5. Release of endogenous amino acids induced by $50 \mathrm{mM}$ potassium from 120 lateral-line stitches perfused with normal levels of calcium $(1.8 \mathrm{mM})$. Column heights are the mean concentrations in fractions 2 and 4 from 6 experiments for the indicated substances. Vertical lines denote standard deviations of the means. * Indicates $50 \mathrm{mM}$ potassium significantly different $(P<0.05)$ from $2.0 \mathrm{mM}$ potassium. 


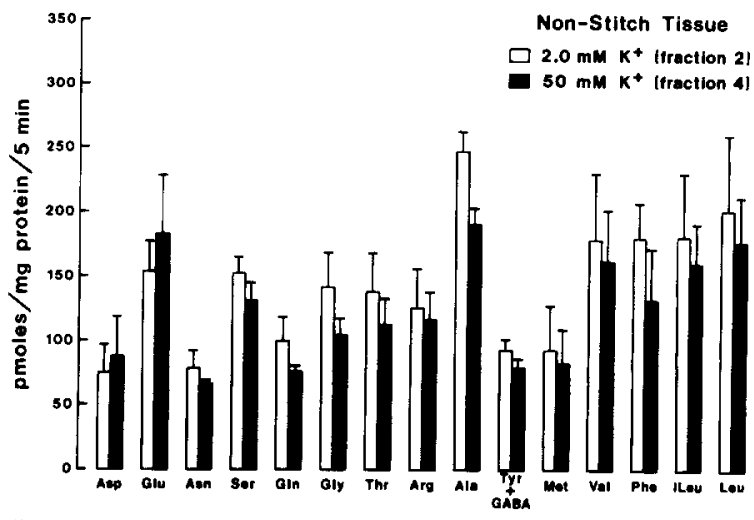

Fig. 6. Release of endogenous amino acids induced by $50 \mathrm{mM}$ potassium from 120 pieces of non-stitch tissue superfused with normal levels of calcium $(1.8 \mathrm{mM})$. Column heights are the mean concentrations in fractions 2 and 4 from 6 experiments for the indicated substances. Vertical lines denote standard deviations of the means.

the 6 experiments with low-calcium medium, both unknowns were not detected in any of the fractions.

To evaluate the dependence of the release on the presence of the lateral line, 6 experiments were performed in which 120 non-stitch pieces of tissue were perfused with standard Ringer solution and subjected to potassium stimulation. Fig. 6 graphically summarizes the results for 15 amino acids identified in fractions 2 and 4 . Overall, the levels of amino acids in the unstimulated samples (fraction 2) appear higher for the non-stitch tissue. Although the mean values for aspartate and glutamate are slightly elevated by potassium (fraction 4), this apparent change is not significant since the levels of aspartate and glutamate were increased in half of the experiments and decreased in the other half. Small increases in unknown Nos. 1 and 2 were also detected in these experiments and exhibited a variability identical to that of aspartate and glutamate. Thus, non-stitch tissue appears capable of producing a pattern of potassium-stimulated release that is comparable to stitch tissue but the changes are variable and not significant.

\section{DISCUSSION}

The results demonstrate that the techniques of in vitro superfusion and potassium depolarization can be successfully used to study the release of endogenous amino acids and other primary amines from the
Xenopus lateral line. The method of superfusion has been extensively utilized to study neurotransmitter release in a number of neural preparations, including brain slices and synaptosomes ${ }^{20}$. It offers the advantages of more precise control of the experimental conditions and of minimizing the cellular uptake of released substances ${ }^{4}$. Although we are the first to apply this methodology to a hair-cell system, it is akin to cochlear perfusion techniques used to study release from the mammalian ear ${ }^{7,24}$. It provides, however, an added advantage over cochlear perfusions in that numerous end organs can be pooled in a small volume to increase the likelihood of detecting substances released in minute amounts. The technique is relatively simple and may be applicable to transmitter release studies on other hair-cell preparations such as pooled vestibular organs or isolated outer hair cells from the mammalian cochlea ${ }^{17}$.

Potassium depolarization in the presence of calcium evoked a specific pattern of primary amine release. The most reproducible increase occurred for glutamate. This is in keeping with our previous demonstration that the natural stimulus of water motion induced a significant increase in the efflux of glutamate when applied to the outer surface of isolated skins containing the lateral line ${ }^{9}$. The present experiments extend these findings by showing that the release of glutamate induced by potassium is blocked by a low-calcium, high-magnesium medium. This suggests release from synaptic elements in a transmitter-like manner and supports the view that glutamate serves a transmitter function in the Xenopus lateral line.

The release of aspartate induced by potassium in the presence of calcium was smaller than that of glutamate and more variable. Aspartate release in response to water motion is also less clear-cut ${ }^{9}$. However, the fact that an increase in aspartate was not detected in any of the present experiments with low-calcium media indicates that aspartate may also play a role in synaptic transmission. Perfusion of lateral-line stitches would be expected to minimize the masking effects of cellular uptake systems on amino acid release. Consequently, the reason for the variability in aspartate release with potassium depolarization is unclear. One explanation may be that aspartate is present in a small, less accessible pool 
and the flow of perfusate may not have been evenly distributed through the tissue. Moreover, the void volume of the perfusion system may have diluted the bolus of potassium so that it did not provide a sufficiently depolarizing stimulus.

In addition to glutamate and aspartate, the release of two unidentified substances was also detected. No attempt was made to quantify the changes in these unknowns since they were not routinely detected in unstimulated samples. Unknown No. 1 appeared in potassium-stimulated samples in 9 out of 10 of the experiments with normal levels of calcium whereas unknown No. 2 was only detected in 5 out of 6 experiments in which 120 stitches were utilized. The fact that neither unknown was released by potassium in low-calcium medium suggests they too may be released in a transmitter-like manner. Whether additional substances might be released by potassium must await experimentation with a greater number of stitches or a perfusion chamber of smaller volume.

Since potassium would be expected to depolarize a number of excitable elements, the detection of substances other than glutamate and aspartate is not unexpected. However, in light of the evidence supporting the notion that the hair-cell transmitter in Xenopus is an excitatory amino acid ${ }^{6,10,12}$, the functional significance, if any, for the release of these unknowns is unclear. It is well established in the nervous system that a host of neuroactive substances termed modulators are released by neurons and glia to modify the synaptic actions of neurotransmitters ${ }^{41}$. Although we cannot exclude the possibility that one or both of the unknowns of the present study serves a more traditional transmitter role, it is tempting to speculate they may function to modulate synaptic processes. In this regard, it is of interest that Sewell and $\mathrm{Mroz}^{37}$ have extracted two unidentified substances from inner ears of fishes which increase the firing rate of afferent nerve fibers in the Xenopus lateral line. Whether the unknowns we have detected correspond to those of Sewell and $\mathrm{Mroz}^{37}$ is not known but their identification should prove to be an interesting area for future study. This may also have relevance for investigators interested in establishing whether substances other than glutamate are endogenous ligands for glutamate receptors in the central nervous system ${ }^{42}$.
High extracellular concentrations of potassium have been successfully used to study the release of endogenous neurotransmitters in several neural systems ${ }^{38,39,43}$. However, it is well known that, aside from depolarizing membranes, potassium can have complex cellular effects and influence the permeability of membranes to amino acids. For example, high concentrations of potassium promote intracellular accumulation of sodium ${ }^{28}$ and have been shown to induce swelling of neurons and glia in the brain $^{25,36}$ and hair cells in the cochlea ${ }^{15}$. These effects can lead to reverse operation of sodiumactivated amino acid transport systems and tissue damage. Along these lines, non-specific release of amino acids including those that are not thought to be neuroactive (e.g. glutamine) have been report$e^{26,32}$. However, in the present study, potassium depolarization evoked the release of glutamate, aspartate and two unknowns but did not increase the efflux of other primary amines. This suggests that potassium did not cause an indiscriminate increase in membrane permeability. Moreover, the specificity of the release and its ionic requirements indicate that the results are not influenced by a generalized increase in cell metabolism which can occur in the presence of high potassium concentrations ${ }^{31}$. The possibility that the perfusion induced degenerative changes (i.e. release of proteolytic enzymes from cells) that contributed to the results also seems unlikely. In this regard, we have examined histologically the integrity of synaptic structures in lateralline organs perfused for $40 \mathrm{~min}$ with standard Ringer solution. In transmission electron micrographs the tissue, including mitochondria, synaptic bodies, vesicles, and afferent and efferent nerve terminals, appears intact and normal (unpublished observations). Based on these considerations, we suggest that the release of glutamate and other substances emanates from synaptic elements by a mechanism that does not differ fundamentally from that known to exist for neurotransmitters in the central nervous system.

Experiments on non-stitch tissue revealed that potassium stimulation released glutamate, aspartate and the two unknowns in 3 out of 6 experiments. Whether this reflects non-specific actions of potassium or a generalized activation of synaptic processes in epithelial tissue remains to be determined. 
In contrast to stitch tissue, the mean increase for glutamate from non-stitch tissue was small and statistically not significant. However, owing to the variance associated with aspartate release, a difference in release between stitch and non-stitch tissue for aspartate was not readily apparent. This is in agreement with our previous report that water motion produced a significantly greater release of glutamate (but not aspartate) from isolated skins containing the lateral line than from skins without the lateral line ${ }^{9}$. Although the release of the unknowns was not quantified, they too appeared to be released more consistently from stitch tissue. This was especially evident for unknown No. 1 which appeared in stimulated fractions in 9 out of 10 experiments with normal levels of calcium. The validity of making a comparison between stitch and non-stitch tissue rests on the essential assumption that the presence of the lateral line constitutes the major difference between the two types of tissue. If this is indeed a valid assumption then it is conceivable that the greater release of glutamate from stitch tissue may reflect release from synaptic elements within the lateral line. Whether a similar conclusion can be drawn for the unknowns must await further experimentation.

A central question arises as to the cellular origin of the potassium-induced release of glutamate. There is ample electrophysiological evidence that high concentrations of potassium ions depolarize hair cells and increase the amount of transmitter release $^{2.18 .27 .40}$. Numerous electrophysiological studies have also shown that transmitter release from hair cells conforms to classical concepts of stimulussecretion coupling, requiring extracellular calcium and being blocked by magnesium ${ }^{13.13,33}$. Voltagedependent calcium channels have also been demonstrated in the basolateral membranes of hair cells in proximity to the release site ${ }^{23}$. Thus, one interpretation of the present results is that glutamate release induced by potassium emanates from hair cells. It should be emphasized, however, that amphibian skin is a heterogenous organ in respect to the types of cellular structures present. For example, several types of exocrine glands have been described ${ }^{29}$. The use of lateral-line organs removed from the skin represents one way of minimizing the possible influence of these glands. Along these lines, the large mucous and granular glands normally present in the dermis are absent in the dermal layer directly beneath each lateral line organ. However, the epidermal layer contains other structures such as epithelial cells, small glands and tactile organs ${ }^{30}$. Moreover, the lateral line neuromasts contain, in addition to hair cells, supporting cells as well as afferent and efferent terminals and fibers. Thus, it is conceivable that glutamate is released from a number of sites. In addition, the variable release observed with non-stitch tissue also suggests that a small contribution from structures unrelated to the sensory epithelium of the lateral line cannot be fully excluded. It is clear that additional experimentation, including the use of ototoxic agents (e.g. neomycin) to destroy hair cells, is needed to clarify the cellular elements involved.

Several studies have attempted to measure a sound-induced release of glutamate into fluids of the mammalian cochlea but with conflicting results (see Bledsoe et al. ${ }^{8}$ for a review). In an attempt to overcome some of the methodological difficulties inherent in in vivo studies on the mammalian ear, Jenison et al. ${ }^{24}$ perfused depolarizing concentrations of potassium through the perilymphatic space of the guinea pig cochlea. In agreement with the present study, they reported a potassium-stimulated, calcium-dependent release of glutamate. However, they also observed a calcium-dependent release of taurine, suggesting a possible species difference between the two hair-cell systems. It should be noted that at present results and those of Jenison et al. ${ }^{24}$ are at variance with a recent study by Drescher et al. ${ }^{19}$. These authors, measuring the release of primary amines from the trout saccular macula with an in vitro static bath technique, reported that the potassium-induced release of glutamate was not calcium-dependent. A clear interpretation of this result is difficult since they also reported the release of aspartate, glycine, GABA, taurine, lysine, arginine, phosphoserine, ethanolamine and $\beta$-alanine. Although a species difference cannot be discounted, the nature of the release profile suggests the condition of the preparation may have influenced the results. Along these lines, there is increasing evidence that non-specific and calcium-independent release of amino acids results from anoxia-induced reversal of amino acid transport systems ${ }^{16,35}$. 
In summary, using an in vitro superfusion technique, potassium depolarization induced a calciumdependent release of glutamate from tissues containing the Xenopus lateral line. A variable release of aspartate and two, as yet, unidentified substances were also detected. Although other interpretations are possible, the results are consistent with the hypothesis that glutamate is a hair-cell transmitter and suggest a potential role for other substances in

\section{REFERENCES}

1 Akoev, G.N. and Andrianov, G.N., The action of divalent ions and drugs on thermal and electric sensitivity of the ampullae of Lorenzini. In T. Szabo and G. Czeh (Eds.), Advances in Physiological Science, Vol. 31, Sensory Physiology of Aquatic Lower Vertebrates, Pergamon, London, 1981, pp. 57-73.

2 Akoev, G.N., Andrianov, G.N. and Sherman, N.O., Effects of potassium ion on the impulse activity of the ampullae of Lorenzini of the skate, Neurosci. Lett., 46 (1984) 341-345.

3 Annoni, J.-M., Cochran, S.L. and Precht, W., Pharmacology of the vestibular hair cell-afferent fiber synapse in the frog, J. Neurosci., 4 (1984) 2106-2116.

4 Baldessarini, R.J. and Kopin, I.J., The effects of drugs on the release of norepinephrine- ${ }^{3} \mathrm{H}$ from central nervous system tissues by electrical stimulation in vitro, J. Pharmacol. Exp. Ther., 156 (1967) 31-38.

5 Bledsoe Jr., S.C., Pharmacology and neurotransmission of sensory transduction in the inner ear. In J.M. Miller (Ed.), Seminars in Hearing, Vol. 7, Thieme, New York, 1986. pp. 117-138.

6 Bledsoe Jr., S.C. and Bobbin, R.P., Effects of $D-\alpha-$ aminoadipate on excitation of afferent fibers in the lateral line of Xenopus laevis. Neurosci. Lett., 32 (1982) 313-320.

7 Bledsoe Jr., S.C., Bobbin, R.P. and Chihal, D.M., Technique for studying sound-induced release of endogenous amino acids from the guinea pig cochlea, Assoc. Res. Otolaryngol. Abstr., 4 (1981) 24.

8 Bledsoe Jr., S.C., Bobbin, R.P. and Puel, J.-L., Neurotransmission in the inner ear. In A.F. Jahn and J.R. Santos-Sacchi (Eds.), Physiology of Hearing, Raven, New York, 1988, pp. 385-406.

9 Bledsoe Jr,, S.C., Bobbin, R.P., Thalmann, R. and Thalmann, I., Stimulus-induced release of endogenous amino acids from skins containing the lateral line organ in Xenopus laevis, Exp. Brain Res., 40 (1980) 97-101.

10 Bledsoe Jr., S.C., Chihal, D.M., Bobbin, R.P. and Morgan, D.N., Comparative actions of glutamate and related substances on the lateral line of Xenopus laevis, Comp. Biochem. Physiol., 75C (1983) 119-206.

11 Bledsoe Jr., S.C., McLaren, J.D. and Meyer, J.R., Potassium-induced, calcium-dependent release of endogenous amino acids from the Xenopus lateral line, Assoc. Res. Otolaryngol. Abstr., 9 (1986) 89.

12 Bobbin, R.P., Bledsoe Jr., S.C., Chihal, D.M. and Morgan, D.N., Comparative actions of glutamate and related substances on the Xenopus lateral line, Comp. Biochem. Physiol., 69C (1981) 145-147. the transduction process, perhaps as neuromodulators.

\section{ACKNOWLEDGEMENTS}

This research was supported by a Program Project Grant (NS-05785) from the National Institutes of Health and a grant from the University of Michigan Biomedical Research Council.

13 Bobbin, R.P., Bledsoe Jr., S.C., Winbery, S., Ceasar, G. and Jenison, G.L., Comparative actions of GABA and acetylcholine on the Xenopus laevis lateral line, Comp. Biochem. Physiol., 80C (1985) 313-318.

14 Bobbin, R.P., Bledsoe Jr., S.C., Winbery, S.L. and Jenison, G.L., Actions of putative neurotransmitters and other relevant compounds on Xenopus laevis lateral line. In D.G. Drescher (Ed.), Auditory Biochemistry, Thomas, Springfield, IL, 1985, pp. 102-122.

15 Bohne, B.A., Mechanisms of noise damage in the inner ear. In D. Henderson, R.P. Hamernick, D.S. Dosanjh and J.H. Mills (Eds.), Effects of Noise on Hearing, Raven, New York, 1976, pp. 41-68.

16 Bradford, H.F., Young, A.M.J. and Crowder, J.M., Continuous glutamate leakage from brain cells is balanced by compensatory high-affinity reuptake transport, Neurosci. Lett., 81 (1987) 296-302.

17 Brownell, W.E., Bader, C.R., Bertrand, D. and de Ribaupierre, Y., Evoked mechanical responses of isolated cochlear outer hair cells, Science, 227 (1985) 194-196.

18 Corey, D.P. and Hudspeth, A.J., Ionic basis of the receptor potential in a vertebrate hair cell, Nature (Lond.), 281 (1979) 675-677.

19 Drescher, M.J., Drescher, D.G. and Hatfield, J.S., Potassium-evoked release of endogenous primary aminecontaining compounds from the trout saccular macula and saccular nerve in vitro, Brain Research, 417 (1987) 39-50.

20 Fagg, G.E. and Lane, J.D., The uptake and release of putative amino acid neurotransmitters, Neuroscience, 4 (1979) 1015-1036.

21 Flock, A., Electron microscopic and electrophysiological studies on the lateral-line canal organ, Acta Otolaryngol., 199 Suppl. (1965).

22 Hill, D.W., Walters, F.H., Wilson, T.D. and Stuart, J.D., High performance liquid chromatographic determination of amino acids in the picomole range, Analyt. Chem., 51 (1979) 1338-1341.

23 Hudspeth, A.J., The ionic channels of a vertebrate hair cell. In A. Flock and J. Wersall (Eds.), Cellular Mechanisms in Hearing, Elsevier, Amsterdam, 1986, pp. 21-27.

24 Jenison, G.L., Bobbin, R.P. and Thalmann, R., Potassium-induced release of endogenous amino acids in the guinea pig cochlea, $J$. Neurochem., 44 (1985) 1845-1853.

25 Kamino, K., Inouye, K. and Inouye, A., Potassium ion-induced swelling of nerve-ending particles by lightscattering measurement, Biochim. Biophys. Acta, 330 (1973) 39-52.

26 Katz, R.I., Chase, T.N. and Kopin, I.J., Effect of ions on stimulus-induced release of amino acids from mammalian brain slices, J. Neurochem., 16 (1969) 961-967. 
27 Leng, G. and Comis, S.D., Effect of increased potassium in scala tympani on auditory nerve sensitivity, Experientia, 35 (1979) 767-768.

28 Lund-Andersen, H. and Hertz, L., Effects of potassium and of glutamate on swelling and on sodium and potassium content in brain-cortex slices from adult rats, Exp. Brain Res., 11 (1970) 199-212.

29 Mills, J.W. and Prum, B.E., Morphology of the exocrine glands of the frog skin, Am. J. Anat., 171 (1984) 91-106.

30 Murray, R.W., The lateralis organs and their innervation in Xenopus laevis, Q. J. Microsc. Sci., 96 (1955) 351-361.

31 McIlwain, H. and Snyder, S.H., Stimulation of pyriform and neocortical tissues in an in vitro flow-system: metabolism properties and release of putative neurotransmitters, J. Neurochem., 17 (1970) 521-530.

32 Roberts, P.J., The release of amino acids with proposed neurotransmitter function from the cuneate and gracile nuclei of the rat in vivo, Brain Research, 67 (1974) 419-428.

33 Robertson, D. and Johnstone, B.M., Effects of divalent cations on spontaneous and evoked activity of single mammalian auditory neurons, Pflügers Arch., 380 (1979) $7-12$.

34 Russell, I.J., Amphibian lateral line receptors. In R. Llinas and W. Precht (Eds.), Frog Neurobiology, A Handbook, Springer, New York, 1976, pp. 513-550.

35 Sanchez-Prieto, J. and Gonzalez, P., Occurrence of a large $\mathrm{Ca}^{++}$-independent release of glutamate during anoxia in isolated nerve terminals (synaptosomes), $J$. Neurochem., 50 (1988) 1322-1324.
36 Schousboe, A., Development of potassium effects on ion concentrations and indicator spaces in rat brain-cortex slices during postnatal ontogenesis, Exp. Brain Res., 15 (1972) 521-531.

37 Sewell, W.F. and Mroz, E.A., Neuroactive substances in inner ear extracts, J. Neurosci., 7 (1987) 2465-2475.

38 Smith, C.C.T., Bowen, D.M. and Davison, A.N., The evoked release of endogenous amino acids from tissue prisms of human neocortex, Brain Research, 269 (1983) 103-109.

39 Toggenburger, G., Felix, D., Cuenod, M. and Henke, H., In vitro release of endogenous $\beta$-alanine, GABA, and glutamate and electrophysiological effect of $\beta$-alanine in pigeon optic tectum, J. Neurochem., 39 (1982) 176-183.

40 Valli, P., Zucca, G. and Casella, C., The importance of potassium in the function of frog semicircular canals, Acta Oto-Laryngol., 84 (1977) 344-351.

41 Vizi, E.S., Non-synaptic Interactions Between Neurons: Modulation of Neurochemical Transmission, John Wiley, New York, 1984, 260 pp.

42 Watkins, J.C. and Evans, R.H., Excitatory amino acid transmitters, Annu. Rev. Pharmacol. Toxicol., 21 (1981) 165-204.

43 Wenthold, R.J., Release of endogenous glutamic acid, aspartic acid and GABA from cochlear nucleus slices, Brain Research, 162 (1979) 338-343.

44 Werman, R., A review: criteria for identification of a central nervous system transmitter, Comp. Biochem. Physiol., 18 (1966) 745-766. 